Article

\title{
Empirical Study on Bikesharing Brand Selection in China in the Post-Sharing Era
}

\author{
Guangnian Xiao *(1) and Zihao Wang \\ School of Economics and Management, Shanghai Maritime University, Shanghai 201306, China; \\ 201930710100@stu.shmtu.edu.cn \\ * Correspondence: gnxiao@shmtu.edu.cn
}

Received: 7 March 2020; Accepted: 11 April 2020; Published: 13 April 2020

check for updates

\begin{abstract}
With the rapid popularization of mobile Internet technology and smart terminal equipment in recent years, the volume and usage of dockless bikesharing (hereafter referred to as bikesharing), which is green, environmentally friendly and convenient, have grown rapidly, making it one of the China's "new four major inventions." The development of the bikesharing in China consists of a pre-sharing era and a post-sharing era. In the pre-sharing era, capital-driven vicious market competition and lack of precise control have led to the abuse of urban space. Since the post-sharing era, the industry structure has returned to rationality, and many participants have been forced out of the market. The bikesharing has formed an oligopoly market consisting of head players such as Hellobike, Mobike, and Ofo. Therefore, how to improve the level of refined operations, promote sustainable development, improve cyclist satisfaction, and contribute to China's strength in transportation have become urgent problems for bikesharing companies and traffic management departments. From the perspective of the cyclist experience, the brand choice of the bikesharing is taken as the research object. An online revealed preference survey is used to collect data on cyclists' socio-economic attributes and subjective evaluations on the bikesharing. The conditional Logit model is used to explore the important factors that influence cyclists on the choice of bikesharing brands. Research results include: (1) age, occupation type, after-tax monthly income of the faculty group, riding comfort, rent, picking up/returning convenience, word of mouth, and volume have a significant impact on cyclists' bikesharing brand choices; (2) gender, educational background, monthly living expenses of the student group, appearance, deposit, deposit returning speed, rate of broken bikes, ease of use of software, and rent discount have no significant impact on cyclists' bikesharing brand choices. The research results are of great significance for improving the service quality of bikesharing companies and promoting the healthy development of the shared economy in China. Based on the results of the study, policy recommendations are made on the improvement for riding comfort, human-centered design, and word of mouth, and the construction of shared facilities.
\end{abstract}

Keywords: post-sharing era; bikesharing; brand choice; conditional Logit model; sustainable development

\section{Introduction}

With the continued growth of the Internet economy in recent years, dockless bikesharing (hereafter referred to as bikesharing) has emerged as a solution to the "last mile" of travel. In comparison with traditional docked shared bikes (hereafter referred to as public bikes), the bikesharing is a new mode of transportation extensively welcomed by travelers, wherein dockless shared bikes (hereafter referred to as shared bikes) can be picked up and returned whenever and wherever possible with convenient use and large volume. The bikesharing is the pathfinder and pioneer of shared economy. The utilization rate of the bikesharing is elevated by separating the ownership and use right of bikes. Risk capitals 
entered the bikesharing industry in a large scale since 2016, facilitating dozens of bikesharing brands to enter the market and contributing to the exponential growth of volume and usage of the bikesharing. Since then, the bikesharing entered a pre-sharing era. However, after 2018, the excessive volume of the bikesharing and "severe winter of capitals" brought most bikesharing brands into a business distress. What bikesharing companies focus on is turned from increasing market share into improving cyclist satisfaction and promoting sustainable development. The pattern of the bikesharing industry tends to stabilize and rationalize, and bikesharing companies gradually enter the profitable phase. Most problems encountered in the pre-sharing era, including management disorder and illegal parking, are solved step by step. According to iiMedia Research [1], growth rates of Chinese bikesharing presented a declining trend in 2018 (Figure 1), but the market scales continued to grow steadily as the rent was elevated by a large margin. The market scale is predicted to reach 30 billion yuan (Figure 2) in 2020 .

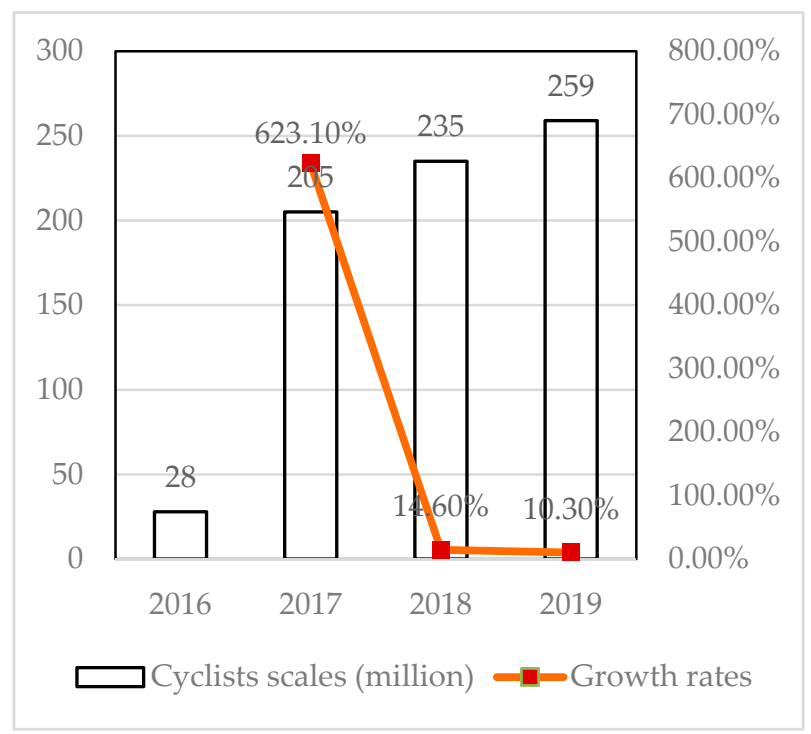

Figure 1. Cyclist scales and growth rates of Chinese bikesharing during 2016 to 2019

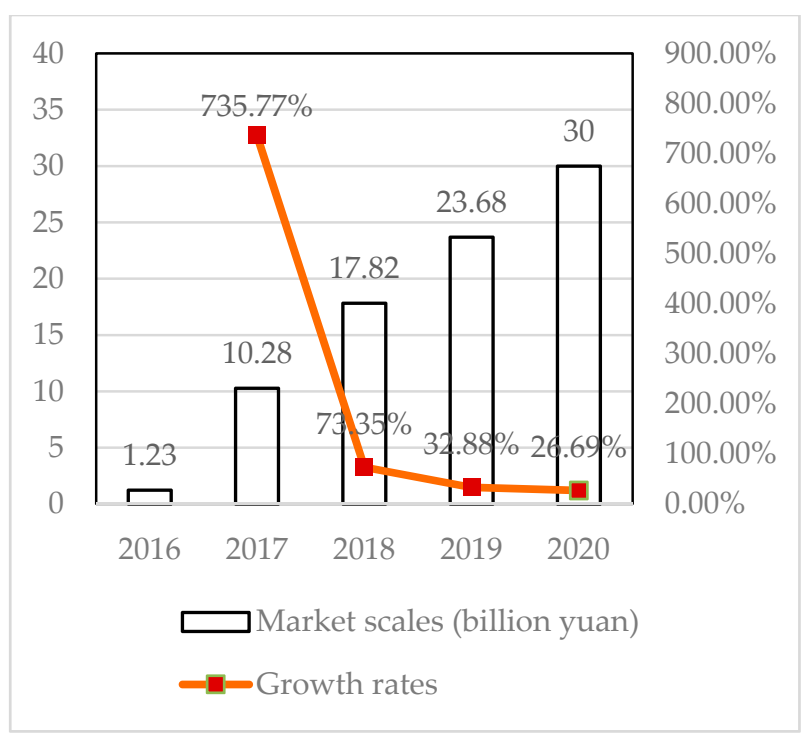

Figure 2. Market scales and growth rates of Chinese bikesharing during 2016 to 2020

In the post-sharing age, the cost used to gain customers is increasing day by day and the demographic dividend is gradually disappearing, so that bikesharing companies are laying a greater emphasis on the refinement of market operation and the precision of customer service. The Deposit-free 
mode is a novel connector between bikesharing companies and the general public. The Deposit-free mode achieves quick success because this mode targets at extensive consumer groups, creating a low-riding threshold, high-riding cost performance, and improved travel experience. In addition, an oligopoly market consisting of Hellobike, Mobike, and Ofo was formed gradually. To compare the basic conditions of three bikesharing companies, deposit, rent, bike design, online picking up/returning operation, membership cards, and rent discount are summarized as shown in Table 1. To compare the relative competitiveness and promote the management of the three brands, we explore bikesharing brand choice with an empirical study.

Table 1. Basic conditions of three bikesharing brands.

\begin{tabular}{|c|c|c|c|c|c|}
\hline Brand & Deposit & Rent & Bike Design & $\begin{array}{l}\text { Online Picking } \\
\text { up/Returning } \\
\text { Operation }\end{array}$ & $\begin{array}{l}\text { Membership Cards } \\
\text { and Rent Discount }\end{array}$ \\
\hline Hellobike & $\begin{array}{l}\text { Deposit-free for over } \\
650 \text { Zhima points and } \\
199 \text { yuan otherwise. }\end{array}$ & 1 yuan/15 min. & $\begin{array}{l}\text { Strong braking force, } \\
\text { large seat area, simple } \\
\text { wheel tread pattern, } \\
\text { and aluminum-alloy } \\
\text { wheel frame. }\end{array}$ & $\begin{array}{c}\text { A dedicated } \\
\text { application and Alipay } \\
\text { interface. }\end{array}$ & $\begin{array}{l}20 \text { and } 16.9 \text { yuan for a } \\
\text { month card and } \\
\text { continuous monthly } \\
\text { payment, temporary } \\
\text { cards ( } 1 \text { yuan/twice, } 2 \\
\text { yuan/five times). }\end{array}$ \\
\hline Mobike & Deposit-free. & $\begin{array}{l}1.5 \text { yuan/first } 15 \\
\text { min and } 0.5 \\
\text { yuan/every } \\
\text { additional } 15 \mathrm{~min} .\end{array}$ & $\begin{array}{l}\text { Wide solid tire, short } \\
\text { axle distance, good } \\
\text { ground gripping force, } \\
\text { and aluminum-alloy } \\
\text { wheel frame. }\end{array}$ & $\begin{array}{c}\text { A dedicated } \\
\text { application, WeChat } \\
\text { small program and } \\
\text { Meituan interface. }\end{array}$ & 20 yuan/month card. \\
\hline Ofo & $\begin{array}{l}199 \text { yuan for } \\
\text { non-student groups. }\end{array}$ & $\begin{array}{l}0.8 \text { yuan } / \mathrm{min} \text { and } \\
0.5 \text { yuan } / \mathrm{km}, \text { but at } \\
\text { most } 2 \text { yuan } / \mathrm{h} .\end{array}$ & $\begin{array}{c}\text { Large tire radius, } \\
\text { heavy bike, and simple } \\
\text { frame design. }\end{array}$ & $\begin{array}{c}\text { A dedicated } \\
\text { application and } \\
\text { WeChat small program } \\
\text { interface. }\end{array}$ & 20 yuan/month card. \\
\hline
\end{tabular}

\section{Literature Review}

The review of existing studies focuses on the bikesharing evolution, the cyclist profile and trip characteristics, and the influential factors for determining cyclists' bikesharing brand choice.

\subsection{Bikesharing Evolution}

The sharing economy improves people's work efficiency, reduces living cost, and monetizes underused resources. With the development of information technologies and the improvement of institutional policies, the shared mobility (including carsharing and bikesharing) gradually has a revolutionary impact on the choice of travel modes [2]. The shared mobility provides users short-term access and modes of transportation on demand. In the urban environment, the shared mobility is affected by the transportation infrastructure, zoning, land use, urban design, housing, and economic development.

Bikesharing provides users with on-demand access for one-way (point-to-point) or round trips from a variety of locations. The abundance of bicycles in dense neighborhoods often creates a "network-effect" that further encourages cycling and other forms of commuting. In addition, bikesharing also contributes to increased mobility, reduced carbon emission, decreased automobile use, economic development, and health benefits [3].

Bikesharing emerged in Europe as a transportation mode in 1965. The bikesharing evolution is categorized into three generations: the first generation (white bikes) that began in Amsterdam in 1965, the second generation (coin-deposit systems) that started in Copenhagen, Denmark in 1995, and the third generation (IT-based systems) that emerged in the Rennes, France city-based system in 1998. The third generation is the prototype of today's bikesharing. In the future, the fourth-generation mode will be characterized by: (1) flexible, clean and dockless characteristics, (2) redistribution innovations; (3) smartcard integration with other transportation modes, and (4) technological advances including GPS tracking, touchscreen kiosks, and electric bikes [4]. 
In addition to the public's use of bikesharing systems, closed campus systems are increasingly deployed in most universities at present. These closed campus systems are available only to the particular campus community they serve and the main service modes of bikesharing in universities are membership-based and non-membership-based self-service models [5]. In the future, bikesharing may receive more attention as a sustainable transportation alternative as a result of rising fuel prices, public health concerns, smart growth initiatives, and climate-change concerns [6].

\subsection{Cyclist Profile and Trip Characteristics}

The cyclist profile is described from socio-economic attributes (including gender, age, educational background, and income) and psychological latent variables. Ran et al. developed a binary Logit model to identify the cyclist profile based on 621 valid questionnaires collected by an online revealed preference (RP) survey from multiple cities, including Shanghai, Beijing, Nanjing, and Hefei [7]. The results indicate that most cyclists are women, young, and highly educated. To compare cyclist profile between shared bikes and private bikes, Buck et al. extracted the profile for cyclists of private bikes from the household travel survey of Washington, DC area in 2007-2008, cyclists of Capital Bikeshare (CaBi) with short-term membership by an intercept survey, and cyclists of CaBi with annual membership by an online survey [8]. The online survey is conducted by sending an email to CaBi's approximately 18000 annual members and asking them to participate in the survey through a survey website. A total of 5464 members completed the survey during a one-month period, with a response rate of $31 \%$. A descriptive statistical analysis shows that $\mathrm{CaBi}$ cyclists with short-term and annual memberships are more likely to be female, young, underpaid, and own few private bikes and cars, compared with cyclists with private bikes. Raux et al. achieved one-day travel diaries and socio-economic attributes of 3161 respondents in Lyon, France with an online survey and analyzed the cyclist profile of the Velo'v bikesharing program [9]. The majority of cyclists with Velo'v annual membership are the young, highly paid, and those who live near bikesharing stations and own private cars. Additionally, cyclists whose bikes were stolen are more willing to take shared bikes $[10,11]$. In terms of psychological latent variables, environmental awareness and subjective norm are positive factors to promote the bikesharing use [12].

The trip characteristics may be reflected by departure time, trip duration, travel distance, trip purpose, travel route, and travel destination, etc. Deng et al. explored the spatio-temporal characteristics of Mobike based on picking up/returning records of 485.5 thousand bikes between 10 to 25 May 2017, and the geographical data extracted from application programming interfaces of Baidu [13]. They concluded that a huge bikesharing demand appears in morning/evening peaks of working days and that bikesharing trips have various characteristics, including tide type, one-way type, loosely connected type, closely connected type, and distance-proof type. In addition, cyclists are more likely to take shared bikes in the weather of no rainfall, light wind, moderate temperature, and clean air quality [14-16]. The top three purposes of bikesharing trips are commuting (35.9\%), entertainment $(22.5 \%)$, and going home (18.1\%). Bikesharing trips are characterized by short travel distance and trip duration. Specifically, over $73.0 \%$ of trips have a trip duration of less than $15 \mathrm{~min}$, and only $5.5 \%$ of trips have a trip duration of over $30 \mathrm{~min}$ [17]. The main reasons for short bikesharing trips are twofold: one is a high proportion of trips for transferring to bus/subway modes, and the other is the marketing activity of "red-packet bikes," which attracts cyclists to ride shared bikes for at least 10 min, rewarded with a red packet of a random amount [18]. Most cyclists prefer travel routes with bike lanes and travel destinations with diversified land use, high transit accessibility, and sufficient parking space [19-22].

\subsection{Influential Factors}

In general, the bikesharing choice is influenced by various factors, including travel distance, picking up convenience, travel time reliability, credit supervision mechanism, social interaction, and service quality. Travel distance is one of the most important factors to influence the travel choice. The bikesharing is preferred for trips with no more than $3 \mathrm{~km}$ [23]. Picking up convenience depends on 
an adequate supply and a reasonable bikesharing distribution. The adequate supply may be ensured by a low supply cost and a huge subsidy on the condition of increasing the company's profit [24]. The reasonable bikesharing distribution lies in an accurate prediction of picking up/returning demand and an efficient redistribution. Dong et al. proposed a model called "DestiFlow" to explore the flow characteristics based on points of interest clustering [25]. DestiFlow is further applied with the time-series location data of Ofo and Mobike. Caggiani et al. suggested a new comprehensive dynamic bike redistribution methodology that comprises a prediction of the picking up/returning demand and a relocation Decision Support System [26]. Zhang et al. further introduced a dynamic pricing scheme with negative prices to achieve a more balanced bikesharing distribution by guiding cyclists to ride from oversupplied areas to undersupplied areas [27]. Travel time reliability for the bikesharing is often believed to be high for trips from and to stations/electrical fences that have a small number of shops within a walking distance [28]. The credit supervision mechanism may work with the condition that the parking behavior of cyclists can be effectively monitored and sanctioned [29]. Yao et al. further demonstrated that the credit supervision mechanism was more appealing to attract cyclists to ride shared bikes when a negative credit is introduced [30]. The social interaction influences cyclists' bikesharing choice by inducing family members or close friends to make the same choices [31]. The service quality is a relatively comprehensive factor and is proved to have a positively significant effect on the intention to ride shared bikes [32].

Another hot topic on the concerning bikesharing is to determine the key factors influencing the bikesharing choice in a specific context. Barbour et al. designed a web-based survey to collect the data on bikesharing usage between February and April, 2018 in the USA and constructed a random parameter Logit model to assess how much a bikesharing trip was displacing an auto trip [33]. They found that age, gender, income, household size, commuting type and length, vehicle ownership, and respondents' body mass index are significant factors for modal substitution decisions. Zhou et al. explored the spatio-temporal patterns of taxi and bikesharing trips in Chicago from 2014 to 2016 [34]. They applied random forests to model the choice between taxies and bikesharing and indicated that travel distance, the number of temporary stops, and recreational facilities played a significant role in determining the choice. Martín et al. developed a multinomial Logit model to investigate individual and contextual factors on the choice of the bikesharing based on data from a household travel survey conducted in 2014 in Vitoria-Gasteiz, Spain [35]. They indicated that age, gender, population density, and mixed land use significantly influenced the bikesharing choice. Li et al. developed a multinomial Logit model to investigate the mode choice among private bikes, public bikes, and shared bikes based on 522 questionnaires conducted in Kunming, China in 2018 [36]. They demonstrated that trips with shared bikes were more likely to be long-distance and for transfer. Moreover, most cyclists of shared bikes are young, underpaid, students, and have no registered permanent residence. Ma et al. constructed a combined model of a factor analysis and a two-layer nested Logit model to explore the factors influencing the riding behavior of the bikesharing for college students [37]. They found that the service quality, rent, mixed traffic, and the number of signal lights at intersection have a significant effect on the bikesharing choice. Du et al. discussed a case study based on the usage data from Mobike in Shanghai and demonstrated that the top three factors influencing the riding frequency were residential areas, parks \& green areas, and population size [38]. Gu et al. compared public bikes and shared bikes from various aspects and concluded that shared bikes may be a better choice in mega cities where local governments had strong control and supervision abilities [39].

Researches on the bikesharing brand selection mainly focuses on analyzing the critical influencing factors of the bikesharing choice, but studies investigating the selection of mainstream bikesharing brands are limited. Therefore, bikesharing brands with top three market shares in China were taken as the study object. We analyze the main factors influencing brand selection with the conditional Logit model. Policy suggestions were proposed for bikesharing companies and related governmental sectors to promote sustainable development of the bikesharing industry. 


\section{Methods}

In the brand choice analyzed in this study, the variables not only include socio-economic attributes of cyclists (cyclist-specific attributes) but also those associated with bikesharing brands (alternative-specific attributes), so that the multinomial Logit model does not apply. Hence, the conditional Logit model [40] is selected to model the choice of bikesharing brands. The conditional Logit model allows us to take into account multiple alternative-specific attributes simultaneously and thus evaluate the effect of these attributes on the choice of bikesharing brands. Additionally, the conditional Logit model has been applied in multiple transportation fields, including carsharing use [41] and travel mode choice [42]. As a member of disaggregate probability models, the conditional Logit model is a discrete choice and analysis method in microeconometrics, and its theoretical basis is that cyclists pursue "utility" maximization when selecting shared bike brands. The random utility function for individual $i$ to select brand $j$ is as follows:

$$
U_{i j}=c_{j}+\sum_{k=1}^{M_{1}} z_{i k} \alpha_{j k}+\sum_{k=1}^{M_{2}} x_{i j k} \beta_{k}+\varepsilon_{i j}(i=1, \ldots, N, j=1,2,3)
$$

where $c_{j}$ is the inherent constant of the shared bike brand $j$, and this constant is zero for Ofo because it is taken as the reference brand; $z_{i k}$ denotes the $k$ th specific variable of the $i$ th cyclist and $\alpha_{j k}$ is the corresponding parameter of the $j$ th brand; $x_{i j k}$ is the $k$ th specific variable of cyclist $i$ and the $j$ th bikesharing brand and $\beta_{k}$ is the corresponding parameter; $M_{1}$ and $M_{2}$ are the numbers of cyclist-specific and alternative-specific attributes; $\varepsilon_{i j}$ is a random error; and $N$ denotes the sample size.

Based on the above random utility function and the theory of random utility maximization, the probability for individual $i$ to select brand $j$ is as follows:

$$
P_{i j}=\frac{\exp \left(c_{j}+\sum_{k=1}^{M_{1}} z_{i k} \alpha_{j k}+\sum_{k=1}^{M_{2}} x_{i j k} \beta_{k}\right)}{\sum_{s=1}^{3} \exp \left(c_{s}+\sum_{k=1}^{M_{1}} z_{i k} \alpha_{s k}+\sum_{k=1}^{M_{2}} x_{i s k} \beta_{k}\right)}(i=1, \ldots, N, j=1,2,3)
$$

\section{Data Collection and Statistical Analysis}

\subsection{Questionnaire Design and Respondent Recruitment}

The questionnaires were designed to analyze the choice of bikesharing brands based on the principles of conciseness, clearness, non-repetition, comprehensiveness, and reasonability. The questionnaire may be divided into the following three parts. The first part involves socio-economic attributes of cyclists, including gender, age, educational background, occupation type, and after-tax monthly income/monthly living expense. The second part consists of subjective evaluations of the three bikesharing brands, including riding comfort, appearance, rent, deposit, deposit returning speed, picking up/returning convenience, word of mouth, rate of broken bikes, ease of use of software (dedicated application and embedded interfaces of other applications), volume, and rent discount. For riding comfort, the question is "Which bikesharing branch do you think provides the greatest riding comfort?" and the options are "A. Hellobike, B. Mobike, C. Ofo, D. No difference." For other subjective evaluations, similar questions are raised. The third part involves the choice of a bikesharing brand that is most commonly used by the respondents. To ensure the quality of the questionnaire, a small-scale pre-survey was performed before the formal survey. The questionnaire and survey plans were adjusted in accordance with the feedback of cyclists.

The target group of this questionnaire survey was college students and faculties. The bikesharing was born to solve the "last mile" travel difficulty of college faculties and students, and offered convenience for their school life. By far, colleges remain an important market for bikesharing companies. College faculties and students are familiar with the bikesharing due to high use frequency. 
Therefore, analyzing the brand choice behaviors for cyclists from faculties and students in colleges may provide a beneficial reference for the sustainable bikesharing development.

\subsection{Descriptive Statistical Results}

An online RP survey was carried out via Wenjuanxing (www.wjx.cn) [43], which is the biggest online Chinese survey platform focusing on questionnaire establishment, distribution, management, and analysis services. The platform is named as "SurveyStar" in English and operated by Changsha Ranxing Science and Technology Ltd. In comparison with the traditional paper-based questionnaire survey, the online survey has many advantages, including online data verification, fast collection, and avoidance of incorrect manual type-in [44,45]. From 29 March 2019 to 1 April 2019, the cyclists were solicited through WeChat Moments and direct invitation. A total of 190 valid questionnaires from students and faculties in colleges were recovered, and most of the cyclists lived in Shanghai. The number of cyclists who filled in and submitted the questionnaires through mobile browser and WeChat are 79 and 111, respectively. The average answering time was $95 \mathrm{~s}$. The numbers of cyclists who choose Hellobike, Mobike, and Ofo are 33 (17.37\%), 63 (33.16\%), and 94 (49.47\%) in this study. According to "China's Shared Bicycle Industry Monitoring Report for the Second Quarter of 2017" [46], the percentages of active cyclists who choose Hellobike, Mobike, and Ofo are $12.10 \%$, $34.00 \%$, and $53.90 \%$. According to the Chi-square test, the brand choice distributions of the sample in this study and the population have no significant difference. The descriptive statistical results of data in the first and the second part of the questionnaire are shown in Tables 2 and 3. Due to the restriction of data availability, we take gender as example to evaluate the sample representativeness in terms of respondents' socio-economic attributes. According to the survey made in Nanjing University of Information Science \& Technology in 2017 [47], the percentages of male and female cyclists are $37.84 \%$ and $62.16 \%$. Based on the Chi-square test, the gender distributions of the sample in this study and the population have no significant difference.

Table 2. Descriptive statistical results of respondents' socio-economic attributes.

\begin{tabular}{cccc}
\hline \multicolumn{2}{c}{ Socio-Economic Attributes } & Quantity & Percentage/\% \\
\hline \multirow{2}{*}{ Gender } & Male & 85 & 44.7 \\
& Female & 105 & 55.3 \\
\hline \multirow{2}{*}{ Age } & $\leq 18$ & 10 & 5.3 \\
& $(18,25]$ & 176 & 92.6 \\
& $(25,30]$ & 0 & 0.0 \\
& $(30,40]$ & 1 & 0.5 \\
& $(40,50]$ & 1 & 0.5 \\
Educational background & $>50$ & 2 & 1.1 \\
\hline & High school or below & 3 & 1.6 \\
Occupation type & Master & 177 & 93.2 \\
& Ph.D. & 9 & 4.7 \\
& Student & 1 & 0.5 \\
\hline & Faculty & 183 & 96.3 \\
Monthly living expense of & $\leq 1000$ & 7 & 3.7 \\
the student group (yuan) & $(1000,2000]$ & 11 & 6.0 \\
& $(2000,3000]$ & 120 & 65.6 \\
& $>3000$ & 46 & 25.2 \\
After-tax monthly income of & $\leq 3000$ & 6 & 3.2 \\
the faculty group (yuan) & $(3000,5000]$ & 0 & 0.0 \\
& $(5000,7000]$ & 1 & 14.3 \\
\hline
\end{tabular}


Table 3. Descriptive statistical results of respondents' subjective evaluations.

\begin{tabular}{|c|c|c|c|c|}
\hline Subjective Evaluations & Mobike (\%) ${ }^{1}$ & Hellobike (\%) & Ofo $(\%)$ & No Difference (\%) \\
\hline Riding comfort & 34.74 & 17.89 & 18.42 & 28.95 \\
\hline Appearance & 36.84 & 13.68 & 20.53 & 28.95 \\
\hline Rent & 11.58 & 12.63 & 39.47 & 36.32 \\
\hline Deposit & 15.26 & 18.42 & 37.37 & 28.95 \\
\hline Deposit returning speed & 35.26 & 15.26 & 18.42 & 31.05 \\
\hline Picking up/returning convenience & 25.79 & 15.79 & 28.95 & 29.47 \\
\hline Word of mouth & 46.32 & 15.26 & 17.89 & 20.53 \\
\hline Rate of broken bikes & 44.21 & 16.84 & 14.74 & 24.21 \\
\hline Ease of use of software & 26.84 & 21.05 & 26.32 & 25.79 \\
\hline Volume & 24.74 & 15.79 & 43.68 & 15.79 \\
\hline Rent discount & 19.47 & 15.26 & 35.26 & 30.00 \\
\hline
\end{tabular}

${ }^{1}$ The second column refers to the percentage of cyclists who think that Mobike is the best, and the following two columns have the same meanings. The last column refers to the percentage of cyclists who think that the three brands make no difference.

\section{Variable Definition and Result Analysis}

\subsection{Variable Definition}

Ofo is taken as the reference brand, so that the corresponding variables and parameters of Hellobike and Mobike but not those of Ofo are defined for individual socio-economic attributes. The socio-economic and subjective evaluation variables are defined in Table 4. For the sake of brevity, $\mathrm{h}, \mathrm{m}$, and $\mathrm{o}$ in the suffixes of variable and parameter names represent Hellobike, Mobike, and Ofo, respectively.

Table 4. Variable definition.

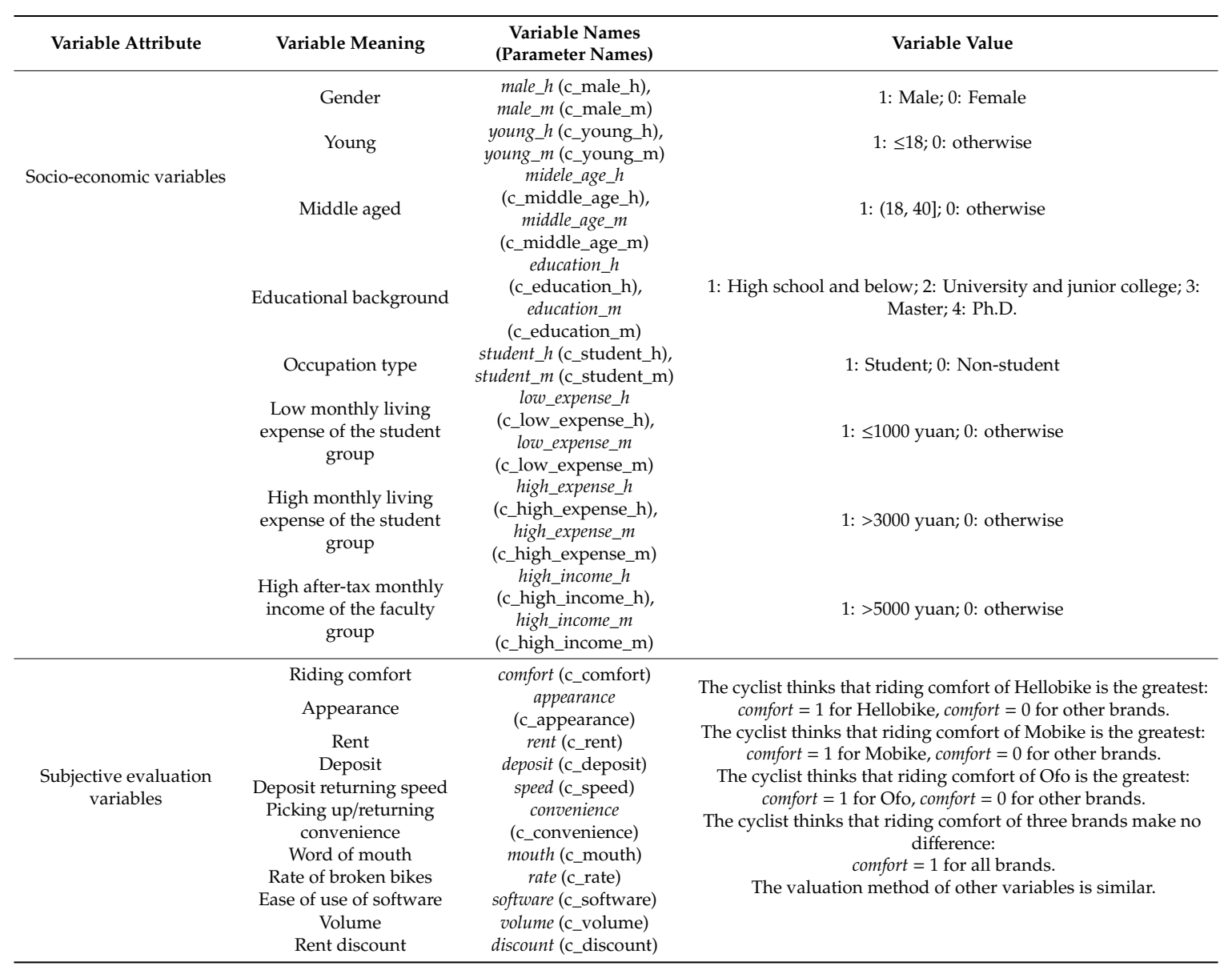




\subsection{Result Analysis}

The parameters of the conditional Logit model were estimated by programming in Stata14.0. In general, a conditional Logit model is believed to be acceptable if the goodness of fit exceeds 0.2 . The goodness of fit in this study is 0.467 , indicating that the model is preferable. The predicted accuracy is $78.54 \%$, which demonstrates that the model had good prediction effect on the choice of bikesharing brands. For the reference brand Ofo, the corresponding coefficients of individual socio-economic variables are all zeros, and those corresponding to other variables are shown in Table 5. At the significance level of $10 \%$, an asterisk is marked at the upper right of the corresponding coefficient of variables with significant influences, and $p$ value is shown in bold.

Table 5. Calibration results.

\begin{tabular}{ccccc}
\hline Parameter Names & Parameter Estimates & $z$ Statistics & $p$ Values & Odds Ratios \\
\hline c_male_h & 0.086 & 0.19 & 0.852 & 1.090 \\
c_male_m & 0.097 & 0.16 & 0.870 & 1.102 \\
c_young_h * & -0.340 & -1.68 & $\mathbf{0 . 0 9 2}$ & 0.712 \\
c_young_m & -0.155 & -0.76 & 0.445 & 0.856 \\
c_middle_age_h & -0.207 & -0.85 & 0.394 & 0.813 \\
c_middle_age_m & -0.192 & -0.68 & 0.495 & 0.825 \\
c_education_h & -0.538 & -0.49 & 0.623 & 0.584 \\
c_education_m & -0.222 & -0.16 & 0.876 & 0.801 \\
c_student_h & 7.332 & 0.72 & 0.4684 & 1528.436 \\
c_student_m * & $10,452.311$ & 2.64 & $\mathbf{0 . 0 0 8}$ & $1.000 \times 10^{30}$ \\
c_low_expense_h & 1.385 & 1.32 & 0.186 & 3.994 \\
c_low_expense_m & -0.383 & -0.22 & 0.824 & 0.682 \\
c_high_expense_h & -0.506 & -0.34 & 0.732 & 0.603 \\
c_high_expense_m & -0.114 & -0.07 & 0.948 & 0.892 \\
c_high_income_h & 2.387 & 1.19 & 0.233 & 10.881 \\
c_high_income_m * & 30.233 & 2.65 & $\mathbf{0 . 0 0 8}$ & $1.349 \times 10^{13}$ \\
c_comfort * & 1.168 & 3.30 & $\mathbf{0 . 0 0 1}$ & 3.214 \\
c_appearance & 0.144 & 0.48 & 0.634 & 1.155 \\
c_rent * & 0.623 & 1.80 & $\mathbf{0 . 0 7 2}$ & 1.865 \\
c_deposit & 0.520 & 1.62 & 0.105 & 1.683 \\
c_speed & -0.197 & -0.58 & 0.561 & 0.821 \\
c_convenience * & 1.325 & 4.60 & $\mathbf{0 . 0 0 0}$ & 3.762 \\
c_mouth * & 0.670 & 1.97 & $\mathbf{0 . 0 4 9}$ & 1.955 \\
c_rate & -0.481 & -1.22 & 0.223 & 0.618 \\
c_software & 0.330 & 1.13 & 0.260 & 1.391 \\
c_volume * & 0.457 & 1.79 & $\mathbf{0 . 0 7 3}$ & 1.579 \\
c_discount & -0.054 & -0.18 & 0.860 & 0.947 \\
\hline Not:*ismakedat & & & & \\
\hline
\end{tabular}

Note: ${ }^{*}$ is marked at the upper right of the corresponding coefficient of variables with significant influences, and $p$ value is shown in bold.

The sample size is relatively small in this study, so that the significance level is set as 0.1 . In other words, when other variables remain unchanged and $p$ value is smaller than 0.1 , the influence of this variable on the choice of other brands is significant relative to the reference brand Ofo; when $p$ value is greater than 0.1 , the influence of this variable on the choice of other brands is insignificant relative to the reference brand Ofo.

The influence of gender is not significant, which is related to the fact that male and female cyclists have no obvious difference in the recognition for the same bikesharing brand. This is consistent with the conclusion of the study by Gu et al. [39]

The age has no significant influence on the choice of Mobike, but it has significant influence on the choice of Hellobike. The young are reluctant to use Hellobike, possibly because Hellobike charges a relatively high rent. In addition, young students are usually freshman, and may participate in less activities than elder students. This contributes to less demand for taking shared bikes. 
The influence of educational background is not significant. The brand choice is closely related to the individual recognition for brands and external variables influencing cyclist experience, rather than relies on excessive professional knowledge.

The occupation type has no significant influence on the brand choice of Hellobike, but it has a significant influence on the brand choice of Mobike. This may be associated with the fact that the rent of Mobike is low, and it can effectively attract cyclists of the student group.

The monthly living expense of the student group has insignificant influence. Overall, the proportion of the bikesharing rent in their living expense is small, and students who usually ride shared bikes generally buy memberships to enjoy the discount of monthly payment, effectively lowering riding costs. Hence, increasing or reducing the living expense has a minor influence on the decision making in the bikesharing brand choice.

The after-tax monthly income of the faculty group has a significant influence. In the post-sharing era, the bikesharing rent has increased by a large margin and even exceeds the expense of subway or bus lines. Because travelers of the faculty group need to complete commuting every day, the rent of shared bikes imposes a burden. In addition, cyclists who take shared bikes are not qualified to enjoy Shanghai's bus transfer discount (1-yuan transportation fee is exempted once a traveler transfers between two bus lines or between a bus line and subway).

The riding comfort has a significant influence. Cycling is an active mode and consumes a lot of physical strength, especially when travel routes include road segments with a certain slope. Although Shanghai is located in a flat region, many signal lamps exist in the city area, greatly impacting the riding speed of shared bikes and increasing the cycling time. Therefore, cyclists tend to choose bikesharing brands with great riding comfort. If a cyclist deems that the riding comfort of Hellobike or Mobike is the greatest, his/her probability of selecting this shared bike brand will increase by 2.214 times relative to the reference brand Ofo.

The appearance has insignificant influence. Like the pathfinder Ofo, companies of other brands usually design their shared bikes with a single color, so that colors of shared bikes were not enough in China in the pre-sharing era. Due to this phenomenon, cyclists generate aesthetic fatigue over the appearance of shared bikes and care less about the appearance. In addition, the main goal for cyclists to use bikesharing is to complete their trips. Hence, the appearance does not generate significant effect on the trip experience and the brand choice.

The rent exerts a significant influence. In the post-sharing era, the main goal of bikesharing companies turns from grabbing market share into ensuring sustainable development. As such, they have lifted up "the tide of rise in price" and reduced the granting frequency and quantity of coupons to explore new profit models. In addition, mileage and rent calculation errors caused by incorrect locating and forgetting to lock the bike occur from time to time. Consequently, cyclists become increasingly sensitive to the rent. If a cyclist thinks that the rent of Hellobike or Mobike is the most reasonable, his/her probability of selecting this bikesharing brand will increase by 0.865 times relative to the reference brand Ofo.

The deposit has an insignificant influence. In the post-sharing era, most bikesharing brands have offered deposit-free ride (or conditional deposit-free ride) across China, relieving consumers from the worry about the "escape" of bikesharing companies and attracting a large batch of new cyclists. Therefore, the deposit has no significant influence on the choice of bikesharing brands.

The influence of deposit returning speed is not remarkable. Except that Ofo only provides students with deposit-free ride, most bikesharing companies have offered deposit-free rides (or conditional deposit-free rides) for all groups. Hence, the deposit insignificantly influences cyclists to select bikesharing brands.

The influence of the picking up/returning convenience is significant. In the pre-sharing era, the volume of shared bikes was enormous, so that cyclists may pick up and return shared bikes almost whenever and wherever. This situation brought great convenience to cyclists. Since the post-sharing era, most cities exercised total volume control, regional restriction, and electronic fences. Hence, 
the convenience for cyclists to pick up and return shared bikes is reduced significantly. Under this circumstance, cyclists may tend to select bikesharing brands with high convenience to pick up and return shared bikes to decrease the trip duration. If a cyclist thinks that the picking up/returning convenience of Hellobike or Mobike is the greatest, his/her probability of choosing this brand will increase by 2.762 times relative to the reference brand Ofo.

The word of mouth has a significant influence. The bikesharing industry is developing rapidly with emerging marketing and management measures in the post-sharing era, including coupons and electronic fences. However, a high time cost is required to acquire the information. Therefore, most cyclists tend to obtain word-of-mouth information of bikesharing brands from relatives and friends or via the Internet to lower the information collection cost when selecting bikesharing brands, which puts the word of mouth into an important factor. If a cyclist believes that the word of mouth of Hellobike or Mobike is the best, his/her probability of choosing this brand will increase by 0.955 times relative to the reference brand Ofo.

The rate of broken bikes has an insignificant influence. With the improvement of production technologies and maintenance level, the quality of shared bikes gradually improves, and the rate of broken bikes gradually declines. In addition, the rate of broken bikes is further decreased by smart locks mounted on shared bikes. The smart lock is embedded with a GPS module and a SIM card, enabling the wireless transmission of positioning and healthy data from shared bikes to a server. The server automatically allocates maintenance and care tasks to proper staff to realize timely detection and processing according to the workload and position of all staff. Hence, the rate of broken bikes has no significant influence on the selection of bikesharing brands.

The influence of the ease of use of software is significant. Besides developing independent applications, the three bikesharing brands have embedded interfaces in common applications (Hellobike-Alipay, Mobike-WeChat small program and Meituan, and Ofo-WeChat small program), improving the accessibility of the software used to take shared bikes. Hence, the ease of use of software has no significant influence of brand selection among cyclists.

The influence of the volume is significant. In the post-sharing era, most cities have implemented total volume control policies and allocated quotas for each bikesharing company to maintain traffic order of non-motor vehicles. After obtaining the quota, each bikesharing company needs to determine the volume in each region according to the predicted demand. In the region with large volume, it is easy for cyclists to find shared bikes, improving cyclists' satisfaction. In addition, cyclists tend to select bikesharing brands with large volume. If a cyclist thinks that the volume of Hellobike or Mobike is the largest, the probability for him/her to choose this brand will increase by 0.904 times relative to the reference brand Ofo.

The rent discount has insignificant influence. In the pre-sharing era, bikesharing companies attracted cyclists with red packets, coupons, and other marketing means, elevating their market shares. However, bikesharing companies rarely granted red packets and coupons within a large scope in the post-sharing era for sustainable development. Hence, the rent discount has no significant influence on the choice of bikesharing brands.

\section{Conclusions}

\subsection{Policy Suggestions for Shared Bike Companies}

(1) Make shared bikes "easier to ride." In the post-sharing era, the riding comfort is one of important variables for cyclists to choose bikesharing brands. Hence, on the premise that the design and manufacturing of shared bikes reach related standards, bikesharing companies should reduce the weight of the frame and tire to the greatest extent and improve the integrating degree between the chain and tires. For example, the light ride series launched by Mobike optimizes the transmission ratio to reduce riding resistance. 
(2) Introduce human-centered design. In the post-sharing era, bikesharing companies should shift the emphasis of the design from cost-effectiveness to humanistic care, and develop more auxiliary functions to serve cyclists. Some bikesharing companies have already made attempts. The rear fender of the fourth-generation shared bikes launched by Hellobike is upgraded into a full-wrapping type, effectively preventing the splash of muddy water. The mode of adjusting seats is changed from the original rotation into a novel wrench to improve the convenience of the adjustment. In addition, a reflection block is installed behind the seat to enhance nighttime riding safety. Besides the above design, bikesharing companies may increase more useful functions, e.g., installing a mobile phone stand at a proper position of the handlebar, so that cyclists can use the navigation of mobile phones safely.

(3) Optimize the rent design. In the post-sharing era, the bikesharing rent is obviously elevated, which reduces the enthusiasm of taking shared bikes. To increase the utilization rate and promote sustainable development, bikesharing companies may take a variety of measures. First, they should take full consideration of the affordability of low-income groups and launch exclusive month cards or coupons dedicated for students and special groups (households enjoying the minimum living guarantee and the unemployed). Second, they may release new membership cards like single-day cards, three-day cards, and week cards to meet diversified demands of more cyclist groups. Third, they should try their best to enhance the business cooperation with businesses, including superstores, commercial complex, and entertainment, to exempt/reduce the rent of cyclists who go to and back from these businesses. The exempted/reduced rent is paid by bikesharing companies and businesses together or businesses alone.

(4) Adjust operation areas and volume dynamically. Unreasonable operation areas and volume of shared bikes lead to difficulties in picking up/returning shared bikes in certain areas. To alleviate the problem of "cold and warm unevenness," bikesharing companies should make accurate demand prediction and redistribute shared bikes in advance to meet the picking up/returning demand. For example, during winter and summer vacations of colleges, shared bikes on camps should be transferred to nearby subway stations, bus stations and residential areas. In addition, bikesharing companies may predict short-time picking up/returning demands with deep learning models considering spatio-temporal dependency based on historical data. The predicted demands contribute to a reasonable determination of the dynamic operation areas and volume.

(5) Plan electronic fences via big data of cycling trajectories. In the post-sharing era, bikesharing companies have erected electronic fences according to governmental requirements and charged a certain dispatching fee for returning shared bikes beyond electronic fences. Although electronic fences have effectively relieved illegal parking of shared bikes, cyclist experience is negatively influenced by unreasonable site selection of electronic fences. Therefore, bikesharing companies should strengthen the analysis of cycling trajectories and conduct systematic planning of site selection of electronic fences. For instance, the Hubble big data platform cooperating with Hellobike connects human-vehicle-life scene through data interaction and drives intelligent full-chain operation like intelligent supply and demand prediction, and intelligent planning of electronic fences, improving the efficiency of Hellobike in managing parking regions of shared bikes.

(6) Improve the word of mouth of cyclists. The word of mouth of cyclists has a significant effect on the brand choice. Besides providing basic services like deposit returning and cyclist service, bikesharing companies should pay high attention to value-added services. For example, they may push the cycling data of shared bikes to social platforms like WeChat Movement, so that cyclists can check the cycling mileage, calorie consumption, ranking and other real-time data. This enhances the loyalty of viscosity of cyclists. They may also establish a donation mechanism of the cycling mileage (mileages accumulated to a certain degree can be donated) to enhance sense of social responsibility of cyclists. 


\subsection{Policy Suggestions for Related Governmental Sectors}

(1) Provide strong support to promote sustainable development of bikesharing companies. Bikesharing companies are usually punished by traffic management departments due to the illegal parking of cyclists. To relieve the negative effect of the illegal parking, traffic management departments should arrange enough staff with law enforcement power to supervise and manage cyclists. Related governmental sectors with right to allocate public resources like fiscal subsidies should provide a certain support to bikesharing companies, and put the bikesharing industry into a new model of mutual benefit and win-win result of the shared economy.

(2) Construct a credit system containing illegal use of shared bikes. Mobike and Hellobike have launched online credit systems, where cyclists will receive credit rewards when using shared bikes legally, but their credits will be deducted if using shared bikes illegally. When the credit of a cyclist is too low, he will fail to enjoy the discount of month cards or other discounts and the rent will be improved. However, this credit system remains at the company level, and illegal cyclists may escape punishments by taking shared bikes of other brands. Therefore, the illegal use behaviors of cyclists should be contained in local public credit information platform, and severe violators should be included into the blacklist of violating social credits.

(3) Construct shared maintenance centers and sheds. The maintenance cost is high due to a large transportation distance of shared bikes between stations and maintenance centers. Hence, traffic management departments may unite bikesharing companies to construct a batch of shared maintenance centers in areas with high volume of shared bikes. Hence, their staff may maintain shared bikes nearby, shortening the maintenance time and increasing the utilization rate of maintenance centers. In addition, severe weather conditions (gale, heavy rain, heavy fog, heavy snow, etc.), may negatively affect the demand of picking up shared bikes sharply and damage shared bikes. Therefore, traffic management departments may unite shared bike companies to construct shared bike sheds in areas with high volume of shared bikes, so that staff store shared bikes temporarily nearby when encountering harsh weather conditions, reducing the rate of broken bikes.

\subsection{Summary and Future Research Direction}

Under the market pattern of oligopoly in the post-sharing era, three main bikesharing brands in China-Hellobike, Mobike, and Ofo-were selected as the study objects. The influences of socio-economic attributes of cyclists and their subjective evaluations for shared bikes on the brand choice was analyzed using the conditional Logit model. The model is calibrated based on the data from an online questionnaire survey. Results indicate that most socio-economic attributes of cyclists (including educational background, occupation type, and after-tax monthly income of the faculty group) and subjective evaluation variables (including riding comfort, rent, picking up/returning convenience, word of mouth, and volume) are important factors deciding the choice of shared bike brands.

Results cannot only be used to make policy suggestions for bikesharing companies and related governmental sectors and promote the sustainable development of shared bikes in China in the post-sharing era, but also provide a basis for traffic management departments to quantitatively evaluate performances of bikesharing companies and determine the total volume and the distribution of the total volume among bikesharing companies. From the angle of cyclists, results reveal the main factors concerned by cyclists who choose bikesharing brands among a minority of competitors in China. From the angle of bikesharing companies, results indicate that bikesharing companies may gradually increase their market shares and support sustainable development by optimizing important factors.

The study may be extended from the following two aspects. On the one hand, GPS data and swiping data of bus IC cards may be used to acquire trip attributes of cyclists, including departure time, trip duration, trip purpose and travel destination. Furthermore, it is possible to analyze the relationship between the choice of bikesharing brands and these trip attributes. On the other hand, it is interesting to collect the choice data of bikesharing brands among cyclists in typical second-tier 
and third-tier cities in China for building the conditional Logit model to compare the key factors influencing the brand choice of cyclists in cities at different tiers.

Author Contributions: Conceptualization, G.X. and Z.W.; methodology, G.X.; software, Z.W.; formal analysis, G.X.; data curation, Z.W.; writing—original draft preparation, G.X.; writing-review and editing, G.X. and Z.W. All authors have read and agreed to the published version of the manuscript.

Funding: This research was funded by National Natural Science Foundation of China, grant number 71701125, 71901196; Shanghai Commission of Science and Technology, grant number 17692109300, 17DZ1204000.

Conflicts of Interest: The authors declare no conflict of interest.

\section{References}

1. $\quad$ iiMedia Research. 2018 China Shared Bikes Development Status Rese arch; iiMedia Research: Hongkong, China, 2018.

2. Cohen, A.; Shaheen, S. Planning for Shared Mobility; American Planning Association: Chicago, IL, USA, 2018.

3. Shaheen, S.; Cohen, A. Shared Micromoblity Policy Toolkit: Docked and Dockless Bike and Scooter Sharing; eScholorship: Berkeley, CA, USA, 2019.

4. Shaheen, S.; Guzman, S.; Zhang, H. Bikesharing in Europe, the Americas, and Asia: Past, present, and future. Trans. Res. Rec. 2010, 2143, 159-167. [CrossRef]

5. Shaheen, S.; Cohen, A.; Zohdy, I. Shared Mobility: Current Practices and Guiding Principles; Federal Highway Administration: Washington, DC, USA, 2016.

6. Shaheen, S.; Martin, E.; Cohen, A.; Finson, R.S. Public Bikesharing in North America: Early Operator and User Understanding; Mineta Transportation Institute: San Jose, CA, USA, 2012.

7. Ran, L.; Li, F. An analysis on characteristics and behaviors of traveling by bike-sharing. J. Transp. Inform. Saf. 2017, 6, 93-100.

8. Buck, D.; Buehler, R.; Happ, P.; Rawls, B.; Chung, P.; Borecki, N. Are bikeshare users different from regular cyclists? A first look at short-term users, annual members, and area cyclists in the Washington, D.C., region. Transport. Res. Rec. 2013, 2387, 112-119. [CrossRef]

9. Raux, C.; Zoubir, A.; Geyik, M. Who are bike sharing schemes members and do they travel differently? The case of Lyon's “Velo'v" scheme. Transport. Res. Part A Policy 2017, 106, 350-363. [CrossRef]

10. Ji, Y.; Fan, Y.; Ermagun, A.; Cao, X.; Wang, W.; Das, K. Public bicycle as a feeder mode to rail transit in China: The role of gender, age, income, trip purpose, and bicycle theft experience. Int. J. Sustain. Transp. 2017, 11, 308-317. [CrossRef]

11. Castillo-Manzano, J.I.; Castro-Nuño, M.; López-Valpuesta, L. Analyzing the transition from a public bicycle system to bicycle ownership: A complex relationship. Transp. Res. Part D Transp. Environ. 2015, 38, 15-26. [CrossRef]

12. Xiao, G.; Wang, R.; Zhang, C.; Ni, A. Demand prediction for a public bike sharing program based on spatio-temporal graph convolutional networks. Multimed. Tools Appl. 2020. [CrossRef]

13. Deng, L.; Xie, Y.; Huang, D. Bicycle-sharing facility planning based on riding spatio-temporal data. Planners 2017, 33, 82-88.

14. Campbell, A.A.; Cherry, C.R.; Ryerson, M.S.; Yang, X. Factors influencing the choice of shared bicycles and shared electric bikes in Beijing. Transp. Res. Part C Emerg. Technol. 2016, 67, 399-414. [CrossRef]

15. Li, W.; Kamargianni, M. Providing quantified evidence to policy makers for promoting bike-sharing in heavily air-polluted cities: A mode choice model and policy simulation for Taiyuan-China. Transp. Res. Part A Policy Pract. 2018, 111, 277-291. [CrossRef]

16. Kim, K. Investigation on the effects of weather and calendar events on bike-sharing according to the trip patterns of bike rentals of stations. J. Transp. Geogr. 2018, 66, 309-320. [CrossRef]

17. Caulfield, B.; O'mahony, M.; Brazil, W.; Weldon, P. Examining usage patterns of a bike-sharing scheme in a medium sized city. Transp. Res. Part A Policy Pract. 2017, 100, 152-161. [CrossRef]

18. Zhang, L. The satisfactory survey for shared bikes in Shijiazhuang urban area. Mod. Bus. Transp. Ind. 2017, 38, 67-68.

19. Faghih-Imani, A.; Eluru, N. Analysing bicycle-sharing system user destination choice preferences: Chicago's divvy system. J. Transp. Geogr. 2015, 44, 53-64. [CrossRef] 
20. Kou, Z.; Cai, H. Understanding bike sharing travel patterns: An analysis of trip data from eight cities. Phys. A Stat. Mech. Appl. 2019, 515, 785-797. [CrossRef]

21. Shen, Y.; Zhang, X.; Zhao, J. Understanding the usage of dockless bike sharing in Singapore. Int. J. Sustain. Transp. 2018, 12, 686-700. [CrossRef]

22. Sun, F.; Chen, P.; Jiao, J. Promoting public bike-sharing: A lesson from the unsuccessful Pronto system. Transp. Res. Part D Transp. Environ. 2018, 63, 533-547. [CrossRef]

23. Zhao, R.; Yang, L.; Liang, X.; Guo, Y.; Lu, Y.; Zhang, Y.; Ren, X. Last-mile travel mode choice: Data-mining hybrid with multiple attribute decision making. Sustainability 2019, 11, 6733. [CrossRef]

24. Chen, Y.; Wang, D.; Chen, K.; Zha, Y.; Bi, G. Optimal pricing and availability strategy of a bike-sharing firm with time-sensitive customers. J. Clean. Prod. 2019, 228, 208-221. [CrossRef]

25. Dong, J.; Chen, B.; He, L.; Ai, C.; Zhang, F.; Guo, D.; Qiu, X. A spatio-temporal flow model of urban dockless shared bikes based on points of interest clustering. ISPRS Int. J. Geo-Inf. 2019, 8, 345. [CrossRef]

26. Caggiani, L.; Camporeale, R.; Ottomanelli, M.; Szeto, W.Y. A modeling framework for the dynamic management of free-floating bike-sharing systems. Transp. Res. Part C Emerg. 2018, 87, 159-182. [CrossRef]

27. Zhang, J.; Meng, M.; David, Z. A dynamic pricing scheme with negative prices in dockless bike sharing systems. Transport. Res. Part B Meth. 2019, 127, 201-224. [CrossRef]

28. Mcbain, C.; Caulfield, B. An analysis of the factors influencing journey time variation in the cork public bike system. Sustain. Cities Soc. 2018, 42, 641-649. [CrossRef]

29. Chen, R. "Bike litter" and obligations of the platform operators: Lessons from China's dockless sharing bikes. Comput. Law Secur. Rev. 2019, 35, 105317. [CrossRef]

30. Yao, Y.; Liu, L.; Guo, Z.; Liu, Z.; Zhou, H. Experimental study on shared bike use behavior under bounded rational theory and credit supervision mechanism. Sustainability 2019, 11, 127. [CrossRef]

31. Manca, F.; Sivakumar, A.; Polak, J.W. The effect of social influence and social interactions on the adoption of a new technology: The use of bike sharing in a student population. Transp. Res. Part C Emerg. 2019, 105, 611-625. [CrossRef]

32. Hsu, C.; Liou, J.; Lo, H.; Wang, Y. Using a hybrid method for evaluating and improving the service quality of public bike-sharing systems. J. Clean. Prod. 2018, 202, 1131-1144. [CrossRef]

33. Barbour, N.; Zhang, Y.; Mannering, F. A statistical analysis of bike sharing usage and its potential as an auto-trip substitute. J. Transp. Health 2019, 12, 253-262. [CrossRef]

34. Zhou, X.; Wang, M.; Li, D. Bike-sharing or taxi? Modeling the choices of travel mode in Chicago using machine learning. J. Transp. Geogr. 2019, 79, 102479. [CrossRef]

35. Martín, B.; Páez, A. Individual and geographic variations in the propensity to travel by active modes in Vitoria-Gasteiz, Spain. J. Transp. Geogr. 2019, 76, 103-113. [CrossRef]

36. Li, X.; Zhang, Y.; Du, M.; Yang, J. Social factors influencing the choice of bicycle: Difference analysis among private bike, public bike sharing and free-floating bike sharing in Kunming, China. KSCE J. Civ. Eng. 2019, 23, 2339-2348. [CrossRef]

37. Ma, S.; Zhou, Y.; Yu, Z.; Zhang, Y. College students' shared bicycle use behavior based on the NL model and factor analysis. Sustainability 2019, 11, 4538. [CrossRef]

38. Du, Y.; Deng, F.; Liao, F. A model framework for discovering the spatio-temporal usage patterns of public free-floating bike-sharing system. Transp. Res. Part C Emerg. 2019, 103, 39-55. [CrossRef]

39. Gu, T.; Kim, I.; Currie, G. To be or not to be dockless: Empirical analysis of dockless bikeshare development in China. Transp. Res. Part A Policy 2019, 119, 122-147. [CrossRef]

40. Mcfadden, D. Conditional logit analysis of qualitative choice behavior. Front. Econom. 1973, 105-142. Available online: http://elsa.berkeley.edu/pub/reprints/mcfadden/zarembka.pdf. (accessed on 29 March 2020).

41. Becker, H.; Ciari, F.; Axhausen, K. Modeling free-floating car-sharing use in Switzerland: A spatial regression and conditional logit approach. Transp. Res. Part C Emerg. 2017, 81, 286-299. [CrossRef]

42. Duy Quy, N.; Amoh-Gyimah, R.; Anh Thi Phuong, T.; Cao Tho, P. Mode choice among university students to school in Danang, Vietnam. Travel Behav. Soc. 2018, 13, 1-10.

43. Wenjuanxing Homepage. Available online: www.wjx.cn (accessed on 29 March 2020).

44. Xiao, G.; Cheng, Q.; Zhang, C. Detecting travel modes using rule-based classification system and Gaussian process classifier. IEEE Access 2019, 7, 116741-116752. [CrossRef] 
45. Xiao, G.; Cheng, Q.; Zhang, C. Detecting travel modes from smartphone-based travel surveys with continuous hidden Markov models. Int. J. Distrib. Sens. Netw. 2019, 15. [CrossRef]

46. iiMedia Research. China's Shared Bicycle Industry Monitoring Report for the Second Quarter of 2017; iiMedia Research: Hongkong, China, 2017.

47. Han, Y.; Dai, H.; Dai, K.; Ma, Y.; Cheng, R. Investigation and Statistical Analysis of Bicycle Sharing on University Campus. Adv. Appl. Math. 2017, 26, 1018-1026. [CrossRef] 